\title{
In-house harmonization of quantitative PCR method validation to determine GM maize events
}

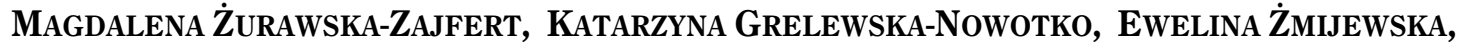

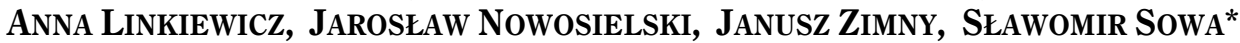 \\ GMO Controlling Laboratory, Department of Plant Biotechnology and Cytogenetics, \\ Plant Breeding and Acclimatization Institute-National Research Institute, Radzików, Błonie, Poland
}

\begin{abstract}
The validation of the methods for the detection and quantification of genetically modified organisms (GMOs) is required as a part of genetically modified food and feed authorization in the European Union (EU). Each validated method must meet the minimum performance requirements for GMO testing methods defined at the EU level. This ensures that the National Reference Laboratories (NRLs), which act as the official control laboratories, use reliable, precise, and robust GMO detection and quantification methods. The NRLs demonstrate their competence by obtaining and maintaining accreditation according to the ISO/IEC 17025 standard. The technical requirements of this standard, primarily related to the tests performed in the laboratory, include all factors that determine the required correctness and reliability of each implemented method. In the process of GMO authorization, applicants can submit any method that fulfills the validation criteria. In turn, the validated methods for the detection and quantification of different GM events in the same species often vary regarding the reference gene assay and PCR conditions. This results in the need of multiple PCR analysis of samples with various GM events. Harmonization of the method validation parameters allows for the detection of different GM events in single PCR run, which simplify the routine laboratory work and decrease the costs of performed tests, therefore improving the efficiency of the official control of the EU market. This is particularly important as the number of authorized GMOs in EU for food and feed is continuously growing. In this study, we report successful quantitative real-time PCR method harmonization for 8 of the $10 \mathrm{GM}$ maize events.
\end{abstract}

Key words: GMO, method validation, quantitative real-time PCR, ISO/IEC 17025, maize

\section{Introduction}

The European Union (EU) legislation on genetically modified food and feed (GMFF) requires the validation of analytical methods as an integral part of GMOs authorization. According to the Regulation (EC) No 1829/2003 on GM food and feed, the application for GMO authorization should include following: methods for sampling, detection, identification, and quantification of the GMO event. Each authorized GMO event results from independent genetic transformation and is unique for DNA sequence. The GMO content of a sample is expressed as the amount of genetically modified material in the total amount of particular species. In quantification with realtime PCR, this value is determined by the measurement of the number of DNA sequences of an endogenous taxon specific reference gene (used as "normalizer") as well as the number of GMO specific target DNA sequences. The GMO detection and quantification analytical methods are developed by the applicant; however, the validation process (according to Regulation (EC) No 1981/2006) is conducted by the European Union Reference Laboratory for Genetically Modified Food and Feed (EURL-GMFF) and by the European Commission (EC) with the assistance of the National Reference Laboratories (NRLs). The number of GMOs authorized in the $\mathrm{EU}$ as food and feed is increasing and once authorization is granted, these GMOs can be present on the market in all the member states. According to the Regulation (EC)

\footnotetext{
* Corresponding author: Plant Breeding and Acclimatization Institute-National Research Institute, Radzików, 05-870 Błonie, Poland; e-mail: s.sowa@ihar.edu.pl
} 
No 882/2004, the NRLs responsible for official control must use reliable, precise, and robust GMO detection methods and must be accredited according to the ISO/IEC 17025 standard. Management and technical requirements are the most important parts of the ISO/IEC 17025 standard. The latter ones are primarily related to the tests performed in the laboratory and include all factors that determine the required correctness and reliability of the applied method. All analytical methods used in the accredited laboratory must be validated. The validation procedure should also take account of technical and financial conditions and should describe the theoretical criteria for the performance of each analytical method. The validation process consists of setting minimum performance requirements for several parameters, including accuracy, the limit of detection, selectivity, linearity, repeatability, reproducibility, uncertainty, and verifies whether each of the particular methods meets the specified criteria.

Minimum performance requirements (MPRs) for the validation of GMO methods are set in the guidance documents of the ENGL (European Network of GMO Laboratories) and EURL-GMFF (ENGL 2015, ENGL 2011). Each method validated by EURL-GMFF must be verified before implementing into routine laboratory work. During verification, most of the parameters included in the method validation studies must be re-evaluated. Method verification ensures that the method meets the validated criteria under the particular laboratory conditions.

There are no legal requirements for PCR instruments, PCR components, and temperature profiles as well as the assays for taxon-specific reference genes (RA) used in GMO methods. Methods submitted for validation of different GMO events are therefore not unified regarding components of PCR and the RA required for quantitative analysis. Lack of harmonization of these parameters results in multiple PCR analysis of samples containing various GM maize events. Up to now, methods with three different maize RA ( $h m g$-high mobility group protein gene, $70 \mathrm{bp}$ fragment of $A d h 1$-alcohol dehydrogenase 1 gene, and $136 \mathrm{bp}$ fragment of $A d h 1$ gene) have been submitted by applicants for validation. This creates additional burden for laboratory work and costs of analysis.

This work presents results of in-house verification of validated PCR-based methods for the determination of
GM maize events. To simplify the analyzes performed in the accredited laboratory, we harmonized some PCR parameters of all implemented methods. The unification includes the use of one RA, the same PCR amplification conditions and the use of one universal PCR Master Mix. All of the presented data were collected during the inhouse verification of validated quantitative analytical methods for different GM events in our laboratory.

\section{Materials and methods}

\section{Materials}

Certified reference materials (CRMs) for $10 \mathrm{GM}$ maize events (Table 1) were purchased from the Institute of Reference Materials and Measurements (Geel, Belgium) and from the American Oil Chemists' Society (USA). All CRMs were certified for GMOs content in the percent of mass fraction.

Table 1. CRMs used in validations

\begin{tabular}{|c|c|c|}
\hline GM event & CRM Code & Producer \\
\hline \multicolumn{3}{|c|}{ Maize CRMs } \\
\hline MIR162 & $\begin{array}{l}\text { 1208-A } \\
0407-A\end{array}$ & \multirow{3}{*}{ AOCS } \\
\hline MON88017 & $\begin{array}{l}\text { 0406-D } \\
\text { 0406-A }\end{array}$ & \\
\hline MON89034 & $\begin{array}{l}\text { 0906-E } \\
0406-\mathrm{A}\end{array}$ & \\
\hline 3272 & ERM-BF420(a,b,c) & \multirow{7}{*}{ IRMM } \\
\hline 98140 & ERM-BF427(a,b,c,d) & \\
\hline MON810 & ERM-BF413(a,b,c,d,e,f) & \\
\hline Bt11 & ERM-BF412(a,b,c,d,e,f) & \\
\hline NK603 & ERM-BF415(a,b,c,d,e,f) & \\
\hline MON863 & ERM-BF416(a,b,c,d) & \\
\hline MON863x810 & ERM-BF417(a,b,c,d) & \\
\hline
\end{tabular}

\section{DNA extraction}

For the DNA extraction, $200 \mathrm{mg}$ analytical samples from CRMs were used in triplicate. Genomic DNA was isolated using the NucleoSpin ${ }^{\circledR}$ Food kit (MachereyNagel, Düren, Germany). This kit was used according to the manufacturer's protocol, with a slight modification in the first lysis step. The analytical sample was treated with $750 \mu \mathrm{l}$ of $\mathrm{CF}$ lysis buffer (instead of $550 \mu \mathrm{l}$ ) and preheated to $65^{\circ} \mathrm{C}$, before $13.6 \mu \mathrm{l} \mathrm{of} 10 \mathrm{mg} / \mathrm{ml}$ ribonu- 
clease A (Sigma-Aldrich, Seelze, Germany) was added. After incubation for $15 \mathrm{~min}$ at $65^{\circ} \mathrm{C}$ with ribonuclease A, $13.6 \mu \mathrm{l}$ of $10 \mathrm{mg} / \mathrm{ml}$ proteinase $\mathrm{K}$ was added. Samples were incubated at $65^{\circ} \mathrm{C}$ for $1 \mathrm{~h}$. After incubation, extraction steps were performed next according to the NucleoSpin ${ }^{\circledR}$ Food protocol.

\section{DNA quantification}

The DNA concentration was measured at $260 \mathrm{~nm}$ and the $260 / 280$ ratios in three replicates using a NanoPhotometer Pearl (Implen, Munich, Germany) or a Lambda $25 \mathrm{UV} /$ Vis spectrophotometer (Perkin Elmer, Waltham, MA, United States).

\section{Real-time PCR conditions}

Analyzes were performed using an ABI 7500 thermocycler (Life Technologies (Thermo Fisher Scientific), Waltham, MA, United States). All real-time PCRs were simplex reactions performed using the TaqMan Universal PCR Master Mix (Life Technologies (Thermo Fisher Scientific), Waltham, MA, United States). The total reaction volume was $25 \mu$ l. The final concentrations for each reagent and method were calculated according to the protocols for GMO quantification methods validated by the EURL-GMFF (2011; http://gmo-crl.jrc.ec. europa.eu/StatusOfDossiers.aspx) - Table 2.

Table 2. Final concentrations for primers and probes [nM] in the quantitative real-time PCR

\begin{tabular}{l|c|c|c}
\hline \multirow{2}{*}{ Target amplicon } & Primer F & Primer R & Probe \\
\cline { 2 - 4 } & \multicolumn{3}{|c}{ Maize } \\
\hline hmg & 300 & 300 & 160 \\
\hline MON810 & 300 & 300 & 180 \\
\hline NK603 & 150 & 150 & 50 \\
\hline Bt11 & 200 & 200 & 150 \\
\hline 3272 & 50 & 900 & 200 \\
\hline 98140 & 500 & 500 & 200 \\
\hline MIR162 & 300 & 300 & 150 \\
\hline MON863 & 150 & 150 & 50 \\
\hline MON88017 & 150 & 150 & 50 \\
\hline MON89034 & 450 & 450 & 100 \\
\hline
\end{tabular}

We used harmonized quantitative real-time PCR time and temperature conditions for all the validated me- thods: the first step was Amperase ${ }^{\circledR}$ UNG activation at $50^{\circ} \mathrm{C}$ for $2 \mathrm{~min}$, followed by $95^{\circ} \mathrm{C}$ for $10 \mathrm{~min}, 15 \mathrm{sec}$ denaturation at $95^{\circ} \mathrm{C}, 60 \mathrm{sec}$ annealing, and chain elongation at $60^{\circ} \mathrm{C}$, which were repeated 45 times.

\section{Primers and probes}

The sequences of the primers and TaqMan probes presented in Table 3 were used according to the methods for GMO quantification officially validated by the EURL-GMFF (2011; http://gmo-crl.jrc.ec.europa.eu/ StatusOfDossiers.aspx).

A fragment of the taxon-specific maize high mobility group protein gene ( $h m g-79 \mathrm{bp}$ ) was used as the RA for all methods (ISO/IEC 2013). The probes were labeled at their $5^{\prime}$-end with the fluorescent reporter dye 6-carboxyfluorescein (FAM) and at 3 '-end with fluorescent quencher dye 6-carboxy-tetramethyl-rhodamine (TAMRA) or molecular-groove binding non-fluorescence quencher (MGBNFQ) (Sigma-Aldrich, Seelze, Germany).

\section{Quantification of GM event content}

For each validated method, the GM event content was calculated from the standard curve using the $\Delta \mathrm{Ct}$ method. The five-point calibration curves were obtained from samples containing fixed percentages of DNA for each analyzed GM event in $100 \mathrm{ng}$ maize DNA. The GM content of the CRMs ranged from 0.1 to $5 \%$ of mass fraction. The calibration curves (reference $\Delta \mathrm{Ct}$-curves) were generated by plotting the $\Delta \mathrm{Ct}$-values of the calibration samples ( $\Delta \mathrm{Ct}$-values measured for the calibration points) against the logarithm of the respective $\mathrm{GM} \%$ content and by fitting a linear regression line to these data. The regression formula was used to estimate the relative amount (\%) of GM events in the tested DNA samples. Then, the slope (a) and the intercept (b) of the calibration curve $(y=a x+b)$ were used to calculate the mean GM event \% content of the tested samples based on their normalized $\Delta \mathrm{Ct}$ values.

\section{Method validation}

All of the event-specific quantitative methods presented in this paper were verified according to the recommendations and requirements specified in the documents of Joint Research Center of the European Commission (ENGL 2015; ENGL 2011; JRC 2011), the ISO/IEC 17025 standard and in-house validation procedures. 
Table 3. Primers and probes used in method validation

\begin{tabular}{|c|c|c|c|c|c|c|c|}
\hline \multirow{2}{*}{$\begin{array}{l}\text { Target } \\
\text { amplicon }\end{array}$} & \multicolumn{2}{|r|}{ Primer F } & \multicolumn{2}{|r|}{ Primer R } & \multicolumn{2}{|r|}{ Probe } & \multirow{2}{*}{$\begin{array}{l}\text { Amplicon } \\
\text { size [bp] }\end{array}$} \\
\hline & name & sequence $\left(5^{\prime} \rightarrow 3^{\prime}\right)$ & name & sequence $\left(5^{\prime} \rightarrow 3^{\prime}\right)$ & name & sequence $\left(5^{\prime} \rightarrow 3^{\prime}\right)$ & \\
\hline \multicolumn{8}{|c|}{ Maize } \\
\hline$h m g$ & ZM1-F & $\begin{array}{l}\text { TTGGACTAGAAATCTCG } \\
\text { TGCTGA }\end{array}$ & ZM1-R & $\begin{array}{l}\text { GCTACATAGGGAGCC } \\
\text { TTGTCCT }\end{array}$ & ZM1 P & $\begin{array}{c}\text { [6FAM]CAATCCACACAAACGCA } \\
\text { CGCGTA[TAM] }\end{array}$ & 79 \\
\hline MON810 & Mail-F1 & $\begin{array}{l}\text { TCGAAGGACGAAGGAC } \\
\text { TCTAACGT }\end{array}$ & Mail-R1 & $\begin{array}{l}\text { GCCACCTTCCTTTTCC } \\
\text { ACTATCTT }\end{array}$ & Mail-s2 & $\begin{array}{c}\text { [6FAM]AACATCCTTTGCCATTGC } \\
\text { CCAGC }[\text { TAM }]\end{array}$ & 92 \\
\hline NK603 & NK603 F & $\begin{array}{c}\text { ATGAATGACCTCGAGT } \\
\text { AAGCTTGTTAA }\end{array}$ & NK603 R & $\begin{array}{l}\text { AAGAGATAACAGGAT } \\
\text { CCACTCAAACACT }\end{array}$ & NK603 P & $\begin{array}{c}\text { [6FAM]TGGTACCACGCGACACA } \\
\text { CTTCCACTC[TAM] }\end{array}$ & 108 \\
\hline Bt11 & Bt11-ev-f1 & $\begin{array}{l}\text { TGTGTGGCCATTTATCA } \\
\text { TCGA }\end{array}$ & Bt11-ev-r5 & $\begin{array}{l}\text { CGCTCAGTGGAACG } \\
\text { AAAACTC }\end{array}$ & Bt11-ev-p1 & $\begin{array}{c}\text { [6FAM]TTCCATGACCAAAATCCC } \\
\text { TTAACGTGAGT[TAM] }\end{array}$ & 68 \\
\hline 3272 & ES3272-F & $\begin{array}{l}\text { TCATCAGACCAGATTCTC } \\
\text { TTTTATGG }\end{array}$ & ES3272-R & $\begin{array}{l}\text { CGTTTCCCGCCTTCA } \\
\text { GTTTA }\end{array}$ & ES3272-P & $\begin{array}{c}\text { [6FAM]ACTGCTGACGCGGCCAA } \\
\text { ACACTG[TAM] }\end{array}$ & 95 \\
\hline 98140 & DP098-f6 & $\begin{array}{l}\text { GTGTGTATGTCTCTTTG } \\
\text { CTTGGTCTT }\end{array}$ & DP098-r2 & $\begin{array}{l}\text { GATTGTCGTTTCCCG } \\
\text { CCTTC }\end{array}$ & DP098-p5 & $\begin{array}{c}\text { [6FAM]CTCTATCGATCCCCCTCT } \\
\text { TTGATAGTTTAAACT [TAM] }\end{array}$ & 80 \\
\hline MIR162 & MIR162-f1 & $\begin{array}{l}\text { GCGCGGTGTCATCTATG } \\
\text { TTACTAG }\end{array}$ & MIR162-r1 & $\begin{array}{c}\text { TGCCTTATCTGTTGCC } \\
\text { TTCAGA }\end{array}$ & MIR162-p1 & $\begin{array}{c}\text { [6FAM]TCTAGACAATTCAGTACA } \\
\text { TTAAAAACGTCCGCCA[TAM] }\end{array}$ & 92 \\
\hline MON863 & MON863-F & $\begin{array}{l}\text { GTAGGATCGGAAAGCT } \\
\text { TGGTAC }\end{array}$ & MON863-R & $\begin{array}{l}\text { TGTTACGGCCTAAAT } \\
\text { GCTGAACT }\end{array}$ & MON863 P & $\begin{array}{c}\text { [6FAM]TGAACACCCATCCGAAC } \\
\text { AAGTAGGGTCA[TAM] }\end{array}$ & 84 \\
\hline MON88017 & MON88017 AF & $\begin{array}{c}\text { GAGCAGGACCTGCAGA } \\
\text { AGCT }\end{array}$ & MON88017 AR & TCCGGAGTTGACCATCCA & MON88017 AP & $\begin{array}{c}\text { [6FAM]TCCCGCCTTCAGTTTAAA } \\
\text { CAGAGTCGGGT[TAM] }\end{array}$ & 95 \\
\hline MON89034 & MON89034-1 & $\begin{array}{l}\text { TTCTCCATATTGACCAT } \\
\text { CATACTCATT }\end{array}$ & MON89034-2 & $\begin{array}{c}\text { CGGTATCTATAATAC } \\
\text { CGTGGTTTTTAAA }\end{array}$ & MON89034 P & $\begin{array}{c}\text { [6FAM]ATCCCCGGAAATTATGTT } \\
{[\mathrm{MGBNFQ]}}\end{array}$ & 77 \\
\hline
\end{tabular}


The following parameters were used to verify the methods: the amplification efficiency, the $\mathrm{R}^{2}$ coefficient, and precision-relative repeatability standard deviation, the limit of quantification, and the limit of detection. These are the most important method validation and verification parameters (ENGL 2015; ENGL 2011; JRC 2011; ISO 2006).

The amplification efficiency (in \%), which correlates with the slope (a) of the standard curve, is calculated using the following equation:

$$
\text { efficiency }=\left(10^{\left(\frac{-1}{\text { slope }}\right)}-1\right) \times 100
$$

The slope of -3.32 corresponds to $100 \%$ efficiency. The average value of the slope of the standard curve shall be in the range of $-3.1 \geq$ slope $\geq-3.6$ (90\% $\geq$ efficiency $\geq 110 \%$ ) (ENGL 2015; ENGL 2011).

The coefficient of determination $\left(\mathrm{R}^{2}\right)$ is calculated as the square of the correlation coefficient (between the measured $\mathrm{Ct}$-value and the logarithm of the concentration) of a standard curve obtained by linear regression analysis. The average of $R^{2}$ value shall be $\geq 0.98$ (ENGL 2015; ENGL 2011).

Precision, which is measured via the relative repeatability standard deviation (RSDr), is the relative standard deviation of test results obtained under repeatability conditions. The test results are obtained in the same laboratory, within short intervals of time, by the same operator, with the same method, on identical test items, and using the same equipment. Precision should be $\leq 25 \%$ over the entire dynamic range of the method (ENGL 2015). The limit of quantification (LOQ) is the lowest amount or concentration of an analyte in a sample that can be reliably quantified with an acceptable level of precision and accuracy. The LOQ should be $<1 / 10$ of the value of the target concentration with an $\mathrm{RSDr} \leq 25 \%$. (ENGL 2015).

The limit of detection (LOD) is the lowest amount or concentration of an analyte in a sample, which can be reliably detected, but not necessarily quantified, as demonstrated by single-laboratory validation. The theoretical LOD should be $<1 / 20$ of the target concentration. Quantitative methods should detect the presence of an analyte at least $95 \%$ of the time at the LOD, ensuring $\leq 5 \%$ false negative results (ENGL 2015). The experimental LOD is estimated in 10 PCR replicates at a low GMO concentration. Then, the LOD is the lowest concentration in a series where all replicates are positive (ENGL 2011).

\section{Results and discussion}

\section{Quality of DNA}

The NucleoSpin Food kit (Macherey-Nagel, Düren, Germany) was used for the isolation of genomic DNA from certified reference materials. This kit is specifically recommended for the extraction of DNA that will be used in PCR methods, including quantitative real-time PCR. We have adapted the kit for the isolation of DNA from various plant materials, including the flower. The efficiency of DNA extraction from the samples ranged between 200 and $800 \mathrm{ng} / \mu \mathrm{l}$ based on spectrophotometric analysis (Table 4) and was suitable for the following quantitative real-time PCR analysis. In some cases, the ratio $\lambda 260 / 280$ for isolated DNA was $>2.0$ indicating possible contamination with RNA.

Table 4. Isolated DNA concentration and purity

\begin{tabular}{|c|c|c|c|c|c|c|c|c|c|c|}
\hline \multicolumn{11}{|c|}{ Maize CRMs } \\
\hline $\begin{array}{l}\text { Event/ } \\
\text { CRM } \\
\text { code }\end{array}$ & $\begin{array}{c}\text { MON810 } \\
\text { ERM- } \\
\text { BF413 }\end{array}$ & $\begin{array}{l}\text { NK603 } \\
\text { ERM- } \\
\text { BF415 }\end{array}$ & $\begin{array}{c}\text { Bt11 } \\
\text { ERM- } \\
\text { BF412 }\end{array}$ & $\begin{array}{c}3272 \\
\text { ERM- } \\
\text { BF420 }\end{array}$ & $\begin{array}{c}98140 \\
\text { ERM- } \\
\text { BF427 }\end{array}$ & $\begin{array}{c}\text { MIR162 } \\
1208-A \\
0407-A\end{array}$ & $\begin{array}{c}\text { MON863 } \\
\text { ERM-BF416 }\end{array}$ & $\begin{array}{c}\text { MON88017 } \\
\text { 0406-D } \\
\text { 0406-A }\end{array}$ & $\begin{array}{c}\text { MON89034 } \\
\text { 0906-E } \\
\text { 0406-A }\end{array}$ & $\begin{array}{c}\text { MON863 } \\
\text { x810 } \\
\text { ERM- } \\
\text { BF417 }\end{array}$ \\
\hline $\begin{array}{l}\text { Concen- } \\
\text { tration } \\
{[\mathrm{ng} / \mu \mathrm{l}]}\end{array}$ & $200-800$ & $200-400$ & $300-800$ & $200-500$ & $200-500$ & $200-600$ & $200-600$ & $200-300$ & $500-800$ & $200-400$ \\
\hline $\begin{array}{c}260 / 280 \\
\text { ratio }\end{array}$ & $1.97-2.10$ & $1.90-2.05$ & $1.90-2.10$ & $1.85-2.00$ & $1.95-2.05$ & $1.95-2.05$ & $1.95-2.10$ & $1.80-1.90$ & $1.85-2.10$ & $1.95-2.10$ \\
\hline
\end{tabular}




\section{In-house method harmonization}

\section{Method selection}

The content of a particular GM event in a sample is quantified by real-time PCR and is expressed as the percentage of the GM maize DNA in relation to the taxonspecific DNA. The GMO percentage is expressed in the mass fraction, which corresponds to the unit of measurement in the certified reference materials used.

The specificity of this method ensures that a set of primers and probes used does not produce any signal when other GM events (or "when non-target DNAs") are tested, meaning this method is exclusively event-specific. For the taxon-specific reference gene sequence, a lack of allelic or copy number variation across the varieties of particular species should be proven. Confirming that this method does not produce any signal for close relatives and for most common crop species is important. These parameters are demonstrated by EURL-GMFF official validation in two ways: by similarity searches in available databases and by experimental verification.

\section{Selection of the maize reference assay}

To select a suitable taxon-specific reference sequence for maize, we searched the literature of previous studies, databases, and GMO validation protocols for a single copy maize-specific sequence with low allelic and copy number variation. The uniformity of the RA for maize across the existing commercial varieties constitutes a problem (Taverniers et al., 2012); since maize genome is highly diverse and the single nucleotide polymorphisms (SNP) are common between inbred maize lines. Some of the endogenous reference sequences used to quantify maize, such as the alcohol dehydrogenase 1 gene (adh1) (Broothaerts et al., 2008) and invertase 1 (ivr1) are not uniform and show sequence polymorphisms and duplication in the genomes of some varieties, affecting quantitative real-time $\mathrm{PCR}$ performance (Papazova et al., 2010). For harmonizing the validated methods, we used high mobility group protein ( $h m g)$ RA for all GM maize event-specific methods. The $79 \mathrm{bp}$ fragment of $h m g$ gene has been already used as the RA in five of ten methods validated by the EURL-GMFF (Table 5). The specific primers and fluorogenic probes were adopted from the event-specific method for quantifying the MON 810 maize event (Biotechnology \& GMO Unit, 2006).

\section{Quantitative real-time PCR assays}

Methods for the detection and quantification of GM maize events validated by the EURL-GMFF (http://gmocrl.jrc.ec.europa.eu/StatusOfDossiers.aspx) apply not only to various taxon-specific RAs, but also to different PCR master mixes and polymerases (five different master mixes), different reaction volumes (from 20 to $50 \mu \mathrm{l}$ ), different PCR times and temperature conditions (temperatures of annealing: $55^{\circ} \mathrm{C}$ or $60^{\circ} \mathrm{C}$, number of cycles: 40,45 , or 50 ), and different amounts of template DNA (100-280 ng). Harmonizing methods for the detection of maize events consisted of the use of: one taxon specific RA, the same PCR time and temperature conditions, one reaction volume, one amount of template DNA (100 ng), and one universal PCR master mix.

Table 5. Endogenous maize reference genes and the corresponding target amplicons

\begin{tabular}{l|c|c|c|c}
\hline \multicolumn{1}{c|}{ GM event } & $\begin{array}{c}\text { Reference gene according to EURL- } \\
\text { GMFF validated methods }\end{array}$ & $\begin{array}{c}\text { Target amplicon } \\
\text { size [bp] }\end{array}$ & $\begin{array}{c}\text { Reference genes used in } \\
\text { method harmonization }\end{array}$ & $\begin{array}{c}\text { Target amplicon } \\
\text { size [bp] }\end{array}$ \\
\hline 3272 & Adh1 & 135 & $h m g$ & 79 \\
\hline 98140 & $h m g$ & 79 & $h m g$ & 79 \\
\hline MON810 & $h m g$ & 79 & $h m g$ & 79 \\
\hline Bt11 & Adh1 & 135 & $h m g$ & 79 \\
\hline NK603 & Adh1 & 70 & $h m g$ & 79 \\
\hline MON89034 & $h m g$ & 79 & $h m g$ & 79 \\
\hline MON863 & Adh1 & 70 & $h m g$ & 79 \\
\hline MON88017 & $h m g$ & 79 & $h m g$ & 79 \\
\hline MIR162 & Adh1 & 135 & $h m g$ & 79 \\
\hline
\end{tabular}

Abbreviations: Adh1 - alcohol dehydrogenase 1 gene, $h m g$ - high mobility group protein gene 


\section{Method validation}

The validations of the quantitative real-time PCR methods for all the tested events were performed using DNA extracted from the certified reference materials.

All of the parameters required by official documents (ENGL 2015; ENGL 2011; JRC 2011; Comm. Reg. No $619 / 2011)$ were calculated. We present the results for the most important parameters, i.e., amplification efficiency, the $R^{2}$ coefficient, precision via the relative repeatability standard deviation (RSDr), the limit of quantification (LOQ), and the limit of detection (LOD). Each method was considered validated only if all of the parameters were in the acceptable range. The validation criteria were fulfilled by 8 of 10 methods (Table 6 ).

\section{Amplification efficiency}

In real-time PCR, $100 \%$ of efficiency corresponds to a slope value of -3.32 . The efficiency of PCR reaction can be influenced by various factors (PCR inhibitors, sequence of the primers, etc.) and is not always ideal. In validation of GMO methods an efficiency value between $90 \%$ and $110 \%$ is considered acceptable $(-3.6 \geq$ slope $\geq-3.1)$. The observed amplification efficiency of the methods met validation criteria in 8 of 10 cases. Two results $87 \%$ and $89 \%$, which were out of the defined range (90\% $\geq$ efficiency $\geq 110 \%$ ), were observed for the 3272 and NK603 maize events, respectively. The best amplification efficiency (99.66\%) was obtained for Bt11 method, where the slope of the reference curve was -3.33 . Very good result was obtained, for MIR162 method, with the slope of the reference curve at -3.30 , which corresponds to $100.92 \%$ amplification efficiency.

\section{Coefficient of determination $\left(R^{2}\right)$}

The coefficient of determination measures the fitness of the linear model to the obtained results. In the validation of GMO method, the mean value of $\mathrm{R}^{2}$ should be $>0.98$ to be considered acceptable. All validated methods met the required criterion as the values of coefficient of determination were above 0.98 . For eight methods, obtained $\mathrm{R}^{2}$ values were above 0.99 , which prove their outstanding fit for the purpose. The $\mathrm{R}^{2}$ values obtained for the other two maize GM events (NK603 and MON863) 0.985 and 0.982 , respectively, were also satisfactory.

\section{Precision-relative repeatability standard deviation (RSDr)}

Precision was calculated for all validated methods for $1 \%$ mass fraction and $0.1 \%$ mass fraction CRMs. This indicates the usefulness of the method for quantification of GMOs at the legal labeling threshold which is $0.9 \%$ in EU for GMOs authorized for food and feed. Estimation of the precision at the $0.1 \%$ is also necessary, because of the legal requirements of the Regulation (EU) 619/2011, which sets the threshold for GMOs that are being in the process of authorizations or withdrawn from the market. The RSDr was estimated with 15 repeats for each validated method. The defined precision in validation of PCR-based methods must be expressed in RSDr $\leq 25 \%$ (ENGL 2015; JRC 2011; Comm. Reg. No 619/2011). The RSDr obtained for $1 \%$ mass fraction CRM of each validated method ranged $4 \%-10 \%$, which is a very good result. The best precision was observed for the maize event MON863 (4\%).

Table 6. Validation parameters for ten maize event-specific methods

\begin{tabular}{l|c|c|c|c|c|c|c}
\hline \multicolumn{1}{|c|}{ GM event } & $\begin{array}{c}\text { LOD (mass fraction) } \\
{[\%]}\end{array}$ & $\begin{array}{c}\text { LOQ (mass fraction) } \\
{[\%]}\end{array}$ & Slope & $\begin{array}{c}\text { Amplification } \\
\text { efficiency [\%] }\end{array}$ & $\mathrm{R}^{2}$ & $\begin{array}{c}\text { RSDr 1 } \\
{[\%]}\end{array}$ & $\begin{array}{c}\text { RSDr 0.1 } \\
{[\%]}\end{array}$ \\
\hline 3272 & 0.025 & 0.1 & -3.67 & 87 & 0.999 & 8 & 24 \\
\hline 98140 & 0.01 & 0.1 & -3.15 & 108 & 0.995 & 10 & 25 \\
\hline MON810 & 0.01 & 0.1 & -3.20 & 105 & 0.997 & 8 & 21 \\
\hline Bt11 & 0.1 & 0.1 & -3.33 & 100 & 0.999 & 9 & 24 \\
\hline NK603 & 0.025 & 0.1 & -3.62 & 89 & 0.985 & 8 & 21 \\
\hline MON89034 & 0.05 & 0.1 & -3.10 & 110 & 0.999 & 7 & 23 \\
\hline MON863 & 0.01 & 0.1 & -3.20 & 105 & 0.982 & 4 & 21 \\
\hline MON88017 & 0.01 & 0.1 & -3.42 & 96 & 0.997 & 7 & 19 \\
\hline MIR162 & 0.025 & 0.1 & -3.30 & 101 & 0.999 & 6 & 19 \\
\hline MON863x810 & $0.01 / 0.025$ & 0.1 & $-3.20 /-3.12$ & $105 / 109$ & $0.998 / 0.999$ & 5 & $18 / 25$ \\
\hline
\end{tabular}


The RSDr obtained for $0.1 \%$ mass fraction CRMs ranged $18-25 \%$ for all maize tested methods. The lowest precision (RSDr 25\%) was observed for 98140 and MON863x810 maize events.

The highest precision was obtained for the MON88017 and MIR162 maize events (19\%) - Table 6. Higher RSDr at the $0.1 \%$ level was expected as the lower the amounts of the analyte, the lower is the precision. The need for the comparability of GMO analysis, performed by various laboratories, requires the use of methods with established precision.

\section{Limit of quantification (LOQ)}

The limit of quantification informs about the minimum level at which the analyte can be reliably quantified (with an acceptable level of precision and accuracy). For all validated methods, the $L O Q$ was defined as the lowest limit of dynamic range and corresponded with $0.1 \%$ mass fraction of the positive control material. The dynamic range is the range of target concentrations over which a method performs in a linear manner with acceptable levels of trueness and precision. As an acceptance criterion, at least $1 / 10$ of the target concentration value must be obtained with five repetitions. The obtained LOQ for each method complied with the requirements for the theoretical $\mathrm{LOQ}$, which is defined as $1 / 10$ of the value of the target concentration with $\mathrm{RSDr} \leq 25 \%$.

\section{Limit of detection (LOD)}

Establishing the LOD value is very important to understand the limitation of applied methods for GMO detection. The LOD of the method should be indicated on every analytical report and is especially informative in the case of "not detected" results. The lowest LOD for the validated methods was achieved with $0.01 \%$ mass fraction reference material which corresponded to 3.7 copies for maize genome. This enables detection of low amounts of GM maize events in samples composed of many species or processed food/feed samples where DNA degradation can be observed. The highest LOD $(0.1 \%$ mass fraction) was obtained for the reference material for Bt11 validated method. Such methods can be applied for routine seed, food and feed testing and are adequate for official control laboratories.

\section{Conclusion}

The growing number of authorized GMO events requires continuous in-house verification of officially vali- dated GMO quantification methods. In the EU, NRLs have to follow legal quality requirements of the methods used for the official control of GMOs. Harmonizing the GMO analytical methods used in all member states would lead to test results that are comparable across the EU. However, analytical efficiency and cost reduction becomes very crucial in the routine workflow of the laboratory. The most important aspects of harmonization are related to the minimum performance requirements for analytical GMO testing methods. Setting specific parameters of the validation procedure ensures that all methods used in the laboratory are fit for the purpose. Harmonization does not necessarily mean that all accredited laboratories involved in GMO testing must use the same, officially validated methods. However, method amendments can be accepted only if the final procedure fulfills the validation requirements. Our results indicate that laboratories can, to some extent, harmonize validated methods for GMO quantification. Harmonizing reference assays and the PCR amplification conditions did not negatively influence the validation parameters of 8 out of 10 maize event-specific methods. The amplification efficiency for most of the methods was in the range of -3.1 $\geq$ slope $\geq-3.6$. The precision (RSDr) of all maize eventspecific methods met the defined validation criteria. The correlation coefficient $\left(\mathrm{R}^{2}\right)$ was above 0.98 for all validations. Because new GMO events are constantly being authorized for food and feed, a flexible scope of accreditation is the best way to implement new methods in the laboratory. Harmonization of in-house validated methods can be a good approach to simplify routine analyzes in accredited GMO laboratories, reduce the cost of performed tests, and increase the efficiency of official control.

\section{Acknowledgments}

This work was supported by Polish Ministry of Agriculture and Rural Development under the multiannual program 2015-2020.

\section{References}

Biotechnology \& GMOs Unit Institute for Health and Consumer Protection DG Joint Research Centre (2006) CRL assessment on the validation of an event specific method for the relative quantitation of maize line MON 810 DNA using real-time PCR as carried out by Federal Institute for Risk Assessment (BfR).

Broothaerts W., Corbisier P., Schimmel H., Trapmann S., Vincent S., Emons H.A. (2008) Single nucleotide polymorphism (SNP839) in the adh1 reference gene affects the quantitation of genetically modified maize (Zea mays L.). J. Agric. Food Chem. 56: 8825-8831. 
ENGL, EURL GMFF (2015) Definition of minimum performance requirements for analytical methods of GMO testing.

ENGL (2011) Verification of analytical methods for GMO testing when implementing interlaboratory validated methods.

EURL-GMFF, ENGL (2011) Compendium of reference methods for GMO analysis.

ISO/IEC (2013) ISO/IEC 21570:2007 A1:2013-06 Foodstuffs - methods of analysis for the detection of genetically modified organisms and derived products - quantitative nucleic acid based methods.

ISO (2006) ISO 24276:2006 Foodstuffs - nucleic acid based methods of analysis for the detection of genetically modified organisms and derived products - general requirements and definitions.

ISO/IEC (2005) ISO/IEC 17025:2005 General requirements for the competence of testing and calibration laboratories.

JRC, EURL GMFF (2011) Technical guidance document from the European Union Reference Laboratory for Genetically Modified Food and Feed on the implementation of Commission Regulation (EU) no 619/2011.

Official Journal of the European Union Commission Regulation (2011) (EU) No 619/2011 of 24 June 2011 Laying down the Methods of Sampling and Analysis for the Official Control of Feed as Regards Presence of Genetically Modified Material for Which an Authorisation Procedure Is Pending or the Authorisation of Which Has Expired.
Papazova N., Zhang D., Gruden K., Vojvoda J., Yang L., Gašparič M.B., Blejec A., Fouilloux S., Loose M.D., Taverniers I. (2010) Evaluation of the reliability of maize reference assays for GMO quantification. Anal. Bioanal. Chem. 396: 2189-2201.

Regulation (EC) No 1829/2003 of the European Parliament and of the Council of 22 September 2003 on genetically modified food and feed. Official Journal of the European Union L 268/1.

Regulation (EC) No 1981/2006 of 22 December 2006 on detailed rules for the implementation of Article 32 of Regulation (EC) No 1829/2003 of the European Parliament and of the Council as regards the Community reference laboratory for genetically modified organisms. Official Journal of the European Union Commission L 368/99.

Regulation (EC) No 882/2004 of the European Parliament and of the Council of 29 April 2004 on official controls performed to ensure the verification of compliance with feed and food law, animal health and animal welfare rules. Official Journal of the European Union L 191/1.

Status of dossiers http://gmo-crl.jrc.ec.europa.eu/Status OfDossiers.aspx.

Taverniers I., Papazova N., Allnutt T., Baumler S., Bertheau Y., Esteve T., Freyer R., Gruden K., Kuznetzov B., Luis La Paz J., et al. (2012) Harmonised Reference Genes and PCRAssays for GMO Quantification. Genetically Modified and Non-Genetically Modified Food Supply Chains: CoExistence and Traceability. Blackwell Publishing Ltd.; John Wiley \& Sons: 273-292. 